\title{
Do state characteristics matter? State level factors related to tobacco cessation quitlines
}

\author{
Paula A Keller, Kalsea J Koss, Timothy B Baker, Linda A Bailey, Michael C Fiore
}

Tobacco Control 2007;16(Suppl I):i75-i80. doi: 10.1136/tc.2006.019745

See end of article for authors' affiliations

\section{Correspondence to:}

Paula A Keller, MPH,

University of Wisconsin

Center for Tobacco Research

and Intervention, University

of Wisconsin School of

Medicine and Public Health

1930 Monroe Street, Suite

200, Madison, WI 5371 1,

USA; pak@ctri.medicine.

wisc.edu

Received 21 December 2006 Accepted 18 April 2007
Background: Quitline services are an effective population-wide tobacco cessation strategy adopted widely in the United States as part of state comprehensive tobacco control efforts. Despite widespread evidence supporting quitlines' effectiveness, many states lack sufficient financial resources to adequately fund and promote this service. Efforts to augment state tobacco control efforts might be fostered by greater knowledge of state level factors associated with the funding and implementation of those efforts.

Methods: We analysed data from the 2004 North American Quitline Consortium survey and from publicly available sources to identify state level factors related to quitline implementation and funding. Factors included in the analyses were state demographic characteristics, tobacco use variables, state tobacco control spending, and economic and political climate variables. Univariate and multivariate regression analyses were conducted.

Results: The best fitting multivariate model that significantly predicted the presence or absence of a state quitline included only cigarette excise tax rate $(p=0.020)$. In terms of funding levels, states with high rates of cigarette consumption $(p=0.047)$ and with higher per capita expenditures for tobacco control programmes $(p=0.0 .004)$ were most likely to spend more on per capita operations budget for quitlines.

Conclusion: State level factors appear to play a part in whether states had established quitlines by mid-2004 and the amount of per capita quitline funding.
$\mathrm{T}$ obacco cessation quitlines are a key component of state based comprehensive tobacco control programmes, providing evidence based telephone cessation counselling on a population-wide basis. The number of state quitlines has grown rapidly over the past decade. In 1992, the first publicly funded state quitline was established in California. By 1999, six states offered quitline services. Currently, all states as well as the District of Columbia offer quitline services to their residents. ${ }^{1}$

A substantial body of evidence attests to the efficacy and effectiveness of quitlines for smoking cessation..$^{2-5}$ A unique characteristic of quitlines is their potential to reach almost the entire population of smokers in a state over time. A smoker merely needs to have access to a telephone to obtain cessation services, eliminating the need to acquire transportation, child care, and other resources in order to obtain assistance to quit. Counselling services are offered at no cost to the caller, further reducing barriers to their use. As a consequence of such widespread access, quitlines have successfully reached virtually all populations of smokers-urban residents, rural residents, the elderly, as well as racial and ethnic minorities. ${ }^{3-9}$

In the United States, most quitlines are funded and operated by state government, though some employers and health insurers offer quitlines for their employees or members, respectively. The Centers for Disease Control and Prevention (CDC) has suggested a model to estimate a minimum funding level for quitline operations. This model is based on an estimate that $2 \%$ of a state's tobacco users will call a quitline each year. This number is then multiplied by an average cost per caller of $\$ 130$ (in 2004 US dollars) to provide an estimate of the minimum funding level required for quitline operations. ${ }^{10}$ Data from the North American Quitline Consortium indicate that in 2004, the actual median annual budget for US quitline operations was $\$ 500000$, not including resources allocated for promotion. ${ }^{11}$

One of the factors limiting states' abilities to reach more smokers via quitlines is lack of sufficient financial resources to adequately fund and promote this service. The continuing reallocation of Master Settlement Agreement funds to nontobacco control areas may further jeopardise funding. ${ }^{12}$ A study by Frist reports that real per capita adjusted total public health spending in the United States in 2000 was $\$ 62.06$, representing just $1.3 \%$ of total health spending. ${ }^{13}$ When expenditures for tobacco control efforts and costs resulting from tobacco use are compared, the business case for greater tobacco control investment becomes increasingly apparent. The CDC reports that the annual health related smoking costs exceed \$167 billion, comprising both productivity losses and excess medical expenditures. ${ }^{14}$ However, in fiscal year 2007, only three states met the CDC's recommended minimum level of investment for tobacco control programmes. ${ }^{15}$

More effective future utilisation of quitlines may depend upon states allocating greater funding for this service. Efforts to augment state tobacco control efforts might be fostered by greater knowledge of state level factors that are related to quitline implementation and support. Unfortunately, little information exists on this topic. Gross et al ${ }^{12}$ evaluated state tobacco control settlement funding and allocations to tobacco control programmes in 2001, finding that only $6 \%$ of these funds were allocated to tobacco control. The authors also found that tobacco producing states and states with higher smoking rates tended to invest fewer funds per capita for tobacco control. Snyder and colleagues ${ }^{16}$ studied whether public opinion regarding tobacco control was influential in state budget decisions in 2001. The authors found that three factors predicted more state funding for tobacco control: citizens who favour more restrictive indoor air policies, a Democratic governor, and lower smoking rate.

The current research was intended to yield evidence on state level factors that are related to tobacco cessation quitline

Abbreviations: CDC, Centers for Disease Control and Prevention; MSA, Master Settlement Agreement 
Table 1 Independent variables and data sources

\begin{tabular}{|c|c|}
\hline Variables & Definitions \\
\hline \multicolumn{2}{|l|}{ Demographic information } \\
\hline Education: high school degree or higher & $\begin{array}{l}\text { Percentage of state population with high school degree or greater (source: US } \\
\text { Census Bureau) }\end{array}$ \\
\hline Age & Median age of state population (source: US Census Bureau) ${ }^{21}$ \\
\hline Income & Median family income of state (source: US Census Bureau) ${ }^{21}$ \\
\hline \multirow{2}{*}{\multicolumn{2}{|c|}{ Square roor or ine foral stare popuiarion (source: Us Lensus bureau) }} \\
\hline & \\
\hline Prevalence & $\begin{array}{l}\text { Percent of adults who smoke in state (source: Centers for Disease Control and } \\
\text { Prevention) }\end{array}$ \\
\hline Consumption & Per capita cigarette pack sales (source: Tobacco Institute) ${ }^{23}$ \\
\hline \multicolumn{2}{|l|}{ Spending for tobacco control } \\
\hline Securitisation of MSA payments & $\begin{array}{l}\text { Whether a state securitised any MSA payments (source: Health Policy } \\
\text { Tracking Service) }\end{array}$ \\
\hline Per capita tobacco control expenditures & $\begin{array}{l}\text { Total state spending on tobacco control divided by state population (sources: } \\
\text { Campaign for Tobacco-Free Kids and US Census Bureau) }\end{array}$ \\
\hline \multicolumn{2}{|r|}{ 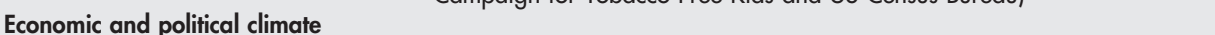 } \\
\hline Cigarette excise tax & Cigarefte excise tax rate per pack (source: Tax Policy Center) ${ }^{25}$ \\
\hline Political ideology & Composite political ideology score (source: Medoff 1997) ${ }^{17}$ \\
\hline $\begin{array}{l}\text { Political affiliation: governor's political } \\
\text { affiliation }\end{array}$ & $\begin{array}{l}\text { Whether the governor is affiliated with a Republican or Democratic party } \\
\text { (source: National Governors Association) }{ }^{26}\end{array}$ \\
\hline $\begin{array}{l}\text { Political affiliation: legislature's political } \\
\text { affiliation }\end{array}$ & $\begin{array}{l}\text { Mean percentage Republican party of both the State Assembly and the State } \\
\text { Legislature (source: The National Conference of State Legislatures) }\end{array}$ \\
\hline State budget deficit & $\begin{array}{l}\text { State's budget deficit as a percentage of the total state budget (source: Center } \\
\text { on Budget and Policy Priorities)" }\end{array}$ \\
\hline Agriculture: tobacco production & $\begin{array}{l}\text { Whether the state produces } \geqslant 1 \text { million pounds of tobacco annually (source: } \\
\text { USDA National Agricultural Statistics Service) }\end{array}$ \\
\hline
\end{tabular}

implementation. By developing a more complete understanding of such factors, state tobacco control programmes, policy makers, and others committed to supporting this evidence based, population focused treatment for tobacco dependence might more effectively advocate for these endeavours. Such findings may also inform efforts to secure state public health funding for areas other than tobacco control.

This report addresses two primary research questions: firstly, what state level variables are related to the presence (vs absence) of a state quitline and, secondly, what state level factors are related to the level of per capita funding for quitline operations? We hypothesised that four categories of variablesdemographics; tobacco use in the state; state spending for tobacco control; and the state's economic and political climate (that is, cigarette excise tax rates, political ideology)—would co-vary reliably with quitline status and per capita funding. We also examined whether these predictor variables differed among states without quitlines, states that recently began quitline services, and states with longer standing quitlines.

\section{METHODS \\ North American Quitline Consortium quitline profile questionnaire}

Data from the 2004 North American Quitline Consortium Quitline Profile questionnaire were used to construct the dependent variables for this study. The survey methodology has been published elsewhere. ${ }^{11}$

Two dependent variables were evaluated in this analysis. The first dependent variable measured whether or not a state had a quitline. States that had quitlines that began providing services on or before 1 June 2004 were coded as having a quitline; those that did not have a quitline by this date were coded as not having a quitline.

The second dependent variable was per capita quitline operations budget for 2004, which was calculated from self reported quitline operating budget data provided by survey respondents and 2004 total state population estimates from the US Census Bureau. Per capita quitline operations budget estimates were used to report spending more accurately, given the wide variation in state population estimates. Quitline operations spending budgets were used versus total quitline budgets because of incomplete information on quitline promotional spending budgets. Only states with operating quitlines at the time of the 2004 North American Quitline Consortium survey were included in this analysis.

Predictor variables were obtained or constructed from publicly available national data sources. Four categories of predictor variables were identified as possible influences in determining quitline status and level of operations spending: (1) state demographic information, (2) state tobacco use rates, (3) investments in tobacco control, and (4) state economic and political climate. The variables and the data sources are listed in table 1. All data were analysed using SPSS (SPSS, version 11.5).

\section{State demographic variables}

Four demographic variables were examined for their impact on state quitlines: (1) the percentage of state population with a high school or degree or higher, (2) the median age of the state's population, (3) the median family income of a state, and (4) the total state population.

\section{State tobacco use variables}

A state's tobacco use was characterised by two variables, prevalence and consumption. Prevalence was defined as the percentage of adult smokers (age 18 and over) who smoked more than 100 cigarettes in their lifetime and currently smoke every day or some days. Cigarette consumption was defined as state specific per capita cigarette pack sales in 2003.

\section{Spending for tobacco control variables}

Variables in this category included securitisation of Master Settlement Agreement (MSA) payments (for example, selling the rights to future MSA payments for an upfront lump sum payment) and per capita tobacco control expenditures. The securitisation variable was created by dividing states into two groups: those that securitised any portion of their MSA payments by 2004 and those that did not. Per capita tobacco control expenditures was a continuous variable, derived from 
Table 2 Univariate results, presence vs absence of a quitline $(n=51)$

\begin{tabular}{|c|c|c|c|c|c|}
\hline Variable & Sig & B & SE & Wald & OR $(95 \% \mathrm{Cl})$ \\
\hline $\begin{array}{l}\text { Demographic information } \\
\text { Education: } \geqslant \text { high school degree } \\
\text { Income } \\
\text { Age } \\
\text { Population }\end{array}$ & $\begin{array}{l}0.518 \\
0.644 \\
0.856 \\
0.448\end{array}$ & $\begin{array}{l}0.059 \\
0.000 \\
0.027 \\
0.000\end{array}$ & $\begin{array}{l}0.091 \\
0.000 \\
0.150 \\
0.000\end{array}$ & $\begin{array}{l}0.419 \\
0.213 \\
0.033 \\
0.576\end{array}$ & $\begin{array}{l}1.060(0.888 \text { to } 1.267) \\
1.000(1.000 \text { to } 1.000) \\
1.028(0.766 \text { to } 1.379) \\
1.000(1.000 \text { to } 1.000)\end{array}$ \\
\hline $\begin{array}{l}\text { Tobacco use } \\
\text { Prevalence } \\
\text { Consumption }\end{array}$ & $\begin{array}{l}0.182 \\
0.298\end{array}$ & $\begin{array}{l}-0.170 \\
-0.12\end{array}$ & $\begin{array}{l}0.127 \\
0.011\end{array}$ & $\begin{array}{l}1.785 \\
1.084\end{array}$ & $\begin{array}{l}0.844 \text { (0.658 to } 1.082) \\
0.988(0.966 \text { to } 1.011)\end{array}$ \\
\hline $\begin{array}{l}\text { Tobacco control spending } \\
\text { Securitisation of MSA payments } \\
\text { Per capita tobacco control } \\
\text { expenditures }\end{array}$ & $\begin{array}{l}0.553 \\
0.192\end{array}$ & $\begin{array}{r}-0.445 \\
0.904\end{array}$ & $\begin{array}{l}0.749 \\
0.694\end{array}$ & $\begin{array}{l}0.352 \\
1.699\end{array}$ & $\begin{array}{l}0.641(0.148 \text { to } 2.764) \\
2.471(0.634 \text { to } 9.625)\end{array}$ \\
\hline $\begin{array}{l}\text { Economic and political climate } \\
\text { Cigarette excise tax rate } \\
\text { Political ideology } \\
\text { Governor's political affiliation } \\
\text { Legislature's political affiliation } \\
\text { State budget deficit } \\
\text { Agriculture: tobacco production } \\
\text { (more than } 1 \text { million lb) }\end{array}$ & $\begin{array}{l}0.020^{*} \\
0.926 \\
0.622 \\
0.938 \\
0.396 \\
0.059\end{array}$ & $\begin{array}{r}2.367 \\
0.002 \\
-0.348 \\
-0.181 \\
0.056 \\
-1.322\end{array}$ & $\begin{array}{l}1.017 \\
0.017 \\
0.707 \\
2.337 \\
0.068 \\
0.701\end{array}$ & $\begin{array}{l}5.416 \\
0.009 \\
0.243 \\
0.006 \\
0.666 \\
3.553\end{array}$ & $\begin{array}{l}10.668(1.453 \text { to } 78.332) \\
1.002(0.969 \text { to } 1.036) \\
0.706(0.177 \text { to } 2.820) \\
0.835(0.009 \text { to } 81.523) \\
1.057(0.925 \text { to } 1.209) \\
0.267(0.067 \text { to } 1.054)\end{array}$ \\
\hline
\end{tabular}

data on total state spending on tobacco control and total state population in 2004 .

\section{Economic and political climate variables}

Included in this category were the following variables: (1) cigarette excise tax rate, (2) political ideology, (3) political affiliation variables, (4) state budget deficit, and (5) tobacco agriculture. The cigarette excise tax rate was measured by the excise tax rate per pack of cigarettes.

Political ideology scores were taken from Medoff's political ideology measure. This scale ranged from 0 to 100 with 100 being the most liberal and 0 being the most conservative. ${ }^{17}$

Two political affiliation variables were used. The first variable, governor's political affiliation in 2004, was coded as a bivariate variable indicating Republican or Democratic Party affiliation. The second variable, legislature's political affiliation, was a composite score representing the political affiliation of both the state senate and state assembly in 2004 .

The state budget deficit variable was a continuous variable and reported as the percentage of the state's total budget for 2004.

The tobacco agriculture variable was created by dividing states into two groups: those that produced less than a million pounds of tobacco annually and those that produced one million or more pounds annually. Since tobacco production is highly concentrated in a small number of states, we dichotomised this distribution for statistical analyses.

\section{Analyses}

All variables were explored for distributional problems (for example, skewness) and effects of outliers above or below three

*We took the following steps to transform predictor variables to correct distributional problems: (1) Population data were skewed, so the data were transformed to the square root of total state population to address distributional problems. Exploratory analyses were conducted to examine the effects of remaining outliers in the population variable. No major changes were found, so outliers remained in the dataset to maintain data. (2) Outliers above or below three standard deviations of the mean in the consumption variable were rescaled, maintaining rank order, to address distributional problems. (3) Per capita tobacco control expenditures were skewed. An inverse transformation did not remove the distributional problem so a median split was conducted. standard deviations of the mean (see footnote* for a summary of transformations). Univariate and multivariate regression analyses were conducted using SPSS to determine possible predictors for the presence and absence of quitlines (SPSS, version 11.5).

A binary logistic regression was performed for each of the variables to predict the presence or absence of a quitline and a linear regression was performed for each of the variables to predict level of per capita quitline operations spending. A variable was considered a significant predictor at the 0.05 alpha level in each univariate model. Best fitting multivariate models were then constructed for each dependent variable. Variables related at 0.20 or less in the univariate analyses were tested for their contributions to a best fitting model using backwards model building strategies published by Hosmer and Lemeshow. ${ }^{18}$ All qualifying variables were placed into the model, and the variable with the lowest Wald coefficient was removed. The process was repeated until all remaining variables in the model were significant at a 0.05 alpha level.

An additional model was built for the per capita quitline operations spending dependent variable. Because of a high degree of correlation between this dependent variable and per capita tobacco control expenditures $(r=0.547)$, this analysis was repeated excluding per capita tobacco control expenditures as a possible predictor to determine whether this correlation was masking other highly significant predictor variables.

One way ANOVAs were performed to examine the differences between states without a quitline, states that recently started a quitline, and states with longer standing quitline services. States that recently started providing quitline services were defined as those states whose quitline began providing services on 1 January 2003 or later. States providing quitline services before 1 January 2003 were classified as states with a longer standing quitline. Three group ANOVAs were conducted with all predictor variables to examine the differences between states with no quitline, states with new quitlines, and states with longer standing quitlines. Two group ANOVAs were also conducted with the states with longer standing quitlines and states without quitlines to examine differences between these two groups of states. 
Table 3 Univariate results, per capita quitline operations spending $(n=38)$

\begin{tabular}{|c|c|c|c|}
\hline Variable & Sig & B & SE $(95 \% \mathrm{Cl})$ \\
\hline $\begin{array}{l}\text { Demographic information } \\
\text { Education: } \geqslant \text { high school degree } \\
\text { Income } \\
\text { Age }\end{array}$ & $\begin{array}{l}0.906 \\
0.263 \\
0.278\end{array}$ & $\begin{array}{l}0.002 \\
-6.100 \mathrm{E}-006 \\
0.021\end{array}$ & $\begin{array}{l}0.013(-0.024 \text { to } 0.027) \\
0.000(0.000 \text { to } 0.000) \\
0.019(-0.017 \text { to } 0.059)\end{array}$ \\
\hline $\begin{array}{l}\text { Tobacco use } \\
\text { Prevalence } \\
\text { Consumption }\end{array}$ & $\begin{array}{l}0.218 \\
0.005^{*}\end{array}$ & $\begin{array}{l}0.019 \\
0.005\end{array}$ & $\begin{array}{l}0.015(-0.012 \text { to } 0.049) \\
0.002(0.001 \text { to } 0.008)\end{array}$ \\
\hline $\begin{array}{l}\text { Tobacco control spending } \\
\text { Securitisation of MSA payments } \\
\text { Per capita tobacco control expenditures }\end{array}$ & $\begin{array}{l}0.793 \\
0.000^{*}\end{array}$ & $\begin{array}{l}0.026 \\
0.052\end{array}$ & $\begin{array}{l}0.100(-0.177 \text { to } 0.230) \\
0.013(0.025 \text { to } 0.079)\end{array}$ \\
\hline $\begin{array}{l}\text { Economic and political climate } \\
\text { Cigarefte excise tax rate } \\
\text { Political ideology } \\
\text { Governor's political affiliation } \\
\text { Legislature's political affiliation } \\
\text { State budget deficit } \\
\text { Agriculture: tobacco production (more than } 1 \\
\text { million lb) }\end{array}$ & $\begin{array}{l}0.289 \\
0.126 \\
0.602 \\
0.778 \\
0.163 \\
0.981\end{array}$ & $\begin{array}{r}-0.116 \\
0.003 \\
-0.049 \\
0.102 \\
-0.008 \\
-0.003\end{array}$ & $\begin{array}{l}0.108(-0.335 \text { to } 0.103) \\
0.002 \text { ( }-0.001 \text { to } 0.008) \\
0.094 \text { ( }-0.240 \text { to } 0.141) \\
0.359 \text { (-0.628 to } 0.832) \\
0.006 \text { (-0.020 to } 0.004) \\
0.114 \text { (-0.234 to } 0.229)\end{array}$ \\
\hline
\end{tabular}

\section{RESULTS}

\section{Presence or absence of a quitline}

Fifty of the 51 US States and the District of Columbia responded to the NAQC survey. Thirty-eight states reported a quitline before 1 June 2004 and 12 states reported no quitline as of 1 June 2004. Univariate logistic regression analyses showed that only one variable, cigarette excise tax rate, independently predicted the presence or absence of a quitline (table 2 ). States with higher cigarette excise tax rates were more likely to have a quitline $(p=0.020)$. For every dollar increase in excise tax rate, the state was 10 times more likely to have a quitline $(\mathrm{OR}=10.67,95 \% \mathrm{CI}=1.45$ to 78.33$)$.

Variables included in the best fitting multivariate model $(\mathrm{p}<0.20$ in the univariate analyses) were (1) adult smoking prevalence, (2) cigarette excise tax rate, (3) tobacco production, and (4) per capita tobacco control expenditures. The best fitting model that significantly predicted the presence or absence of a quitline included only cigarette excise tax rate $(p=0.020)$.

Three-group, one way ANOVAs (data not shown) showed that cigarette excise tax $(p=0.034)$ was the only variable that was significantly different between the states with no quitline (mean 0.045, SD 0.44), states with a new quitline (mean 0.67, SD 0.31), and states with a longer standing quitline (mean 0.85 , SD 0.47). An LSD post hoc test showed that states with no quitline had a significantly lower cigarette excise tax rate than states with a longer standing quitline. Both prevalence $(\mathrm{p}=0.065)$ and tobacco production $(\mathrm{p}=0.104)$ variables approached statistical significance. Two-group, one way ANOVAs showed similar results with excise tax $(p=0.014)$ being the only variable that was significantly different between states with longer standing quitlines and states without quitlines. Again prevalence $(\mathrm{p}=0.095)$ and tobacco production $(\mathrm{p}=0.054)$ variables approached statistical significance in the two-group analyses.

\section{Per capita operations spending}

Only states that reported having a quitline at the time of the 2004 North American Quitline Consortium survey were included in the analysis of per capita operations spending $(n=38)$. Two variables significantly predicted the amount of per capita quitline operations spending in the univariate analyses: higher levels of cigarette consumption $(p=0.005)$, and greater state spending on tobacco control $(p=0.000)$ (table 3$)$. The political ideology variable $(p=0.126)$ and the state budget deficit variable $(\mathrm{p}=0.163)$ approached statistical significance.

Variables included in the best fitting model $(\mathrm{p}<0.20$ in the univariate analyses) were (1) cigarette consumption, (2) per capita tobacco control expenditures, (3) political ideology, and (4) budget deficit. The best fitting model predicting per capita quitline operations spending comprised only two variables: per capita tobacco control expenditures and cigarette consumption. States with high levels of cigarette consumption $(p=0.047)$ and who had higher per capita expenditures for tobacco control programmes $(p=0.004)$ were most likely to spend more on per capita operations budget for quitlines.

This analysis was repeated excluding per capita tobacco control expenditures as a possible predictor. The goal of this additional analysis was to determine whether the correlation between per capita quitline operations spending and per capita tobacco control spending $(\mathrm{r}=0.547)$ was masking other highly significant predictor variables. In this analysis, cigarette consumption was the only variable that predicted larger amounts of per capita operations spending on quitlines $(\mathrm{p}=0.005)$.

\section{DISCUSSION}

These findings represent an initial analysis of state level factors that may influence whether a state has a quitline as well as per capita funding for quitline services among states with quitlines. Cigarette excise tax rate was the only variable in both univariate and multivariate analyses that predicted whether a state had a quitline. Excise tax rate was a robust indicator of presence or absence of a quitline-for every dollar increase in cigarette excise tax rate, the likelihood of the state having a quitline increased 10-fold.

This finding is consistent with policymaker and advocate recommendations that at least a portion of cigarette excise tax increases be dedicated to fund tobacco control programmes that increasingly include quitlines. ${ }^{19}$ Of course, this relation may not be causal as cigarette excise tax levels and quitline implementation may both reflect the actions of some third variable such as presence of state level tobacco control champions or concerns about the health and economic effects of tobacco use. Indeed, it is likely that tax rate is a net outcome of multiple factors; however, this does not mean that it does not directly affect 
quitline expenditures. Another possible explanation could be that the presence of a quitline and a higher cigarette excise tax rate may represent a greater commitment to tobacco control at the state level.

We also found that per capita expenditures for quitlines were predicted by only two variables: per capita state expenditures for tobacco control and cigarette consumption. The relation between per capita spending for tobacco control and quitlines is logical in that most states with tobacco control programmes include quitlines and that the CDC recommendations for comprehensive tobacco control programmes include quitlines. ${ }^{20}$ It makes sense to infer that states that are more likely to invest in tobacco control are similarly more likely to invest in quitlines, and our results support this inference. This suggests that concern about health and economic impacts in states with high smoking prevalence may encourage adoption of tobacco control programmes.

The relation between per capita spending for quitlines and cigarette consumption is less clear. A possible explanation is that states with higher levels of cigarette consumption invest more aggressively in quitline services in an effort to drive down both prevalence and tobacco use rates. An alternative explanation is that states with higher levels of cigarette consumption dedicate more of their overall tobacco control programme funds to quitlines than to comprehensive tobacco control programmes, seeing quitlines as more politically palatable than other approaches.

We did not detect a relation between our dependent variables and any state demographic variables. We assume that the demographic factors included in our analyses (education, age, income, and population) are less relevant for issues regarding state level funding of quitlines than other factors. Unlike other researchers, we did not detect a relation between our dependent variables and our political climate variables (for example, state political ideology and political affiliation), as well as other economic variables (for example, magnitude of state budget deficits). It is possible that political climate may be less significant with regard to quitline expenditures at the time of our study than in previous years. This could be because of maturing and relative stabilisation of tobacco control funding since the recession in the early years of this decade, incorporation of quitline funding into overall state tobacco control funding (thus "protecting" or insulating it from political influences), or to other factors at the state level that we were unable to measure. It could also reflect the fact that the need for tobacco control has become more broadly recognised across the ideological spectrum.

Our findings differ somewhat from two previous studies in this field. Gross and colleagues, ${ }^{12}$ using data from 2001, found that states with the highest rates of smoking tended to invest less per capita in tobacco control programmes. In our analyses, this inverse relation was not observed. Two factors may account for this difference. Firstly, our analyses were based on 2004 data and this later time point may reflect a maturing of tobacco control priorities within states. Specifically, as states over time dedicate less of their MSA funding to tobacco control, states with higher consumption rates may be under stronger pressure to continue to expend resources on tobacco control. Additionally, the decision making process regarding quitline funding specifically, rather than tobacco control funding more broadly may differ within the various states.

In another article that examined variables associated with state tobacco control funding, Snyder and colleagues ${ }^{16}$ found that three factors predicted more state funding for tobacco control: citizens who favour more restrictive indoor air policies, a Democratic governor, and lower smoking rate (a finding similar to that of Gross and colleagues). Our analysis did not

\section{What is known about this topic}

Despite widespread evidence supporting the effectiveness of quitlines, many states lack sufficient financial resources to adequately fund and promote this service. Efforts to augment state tobacco control efforts might be fostered by greater knowledge of state level factors associated with the funding and implementation of quitlines. To date, this topic has not been studied.

assess citizen attitudes towards smoke-free air and thus, we can't comment on that association. We did not demonstrate an association with level of smoking or party affiliation of the governor. As with Gross, the different finding regarding the association between smoking rate and per capita tobacco control funding may reflect changes and maturing in tobacco control funding priorities over time between 2001 (the basis of the Gross and Sydner analyses) and 2004 (the basis of our analyses).

Limitations of this study include reliance on multiple publicly available data sources rather than collecting primary data on the independent variables included in our analysis, reliance on self reported quitline operating budget data, and the use of correlational research strategies that limit causal inference. Moreover, the analyses do not allow us to address the possibility that our dependent variables (for example, quitline presence and per capita quitline operations funding) may be correlated with other unmeasured variables.

This analysis found that select state level factors appear to play a part in whether states had established quitlines by mid-2004 and the amount of per capita quitline funding. Higher cigarette excise tax rates may indicate an interest on the part of policy makers to seek policy solutions to drive down cigarette consumption, increase state tax revenues to fund tobacco control and other programmes, or both. Policy makers and advocates may wish to evaluate whether other product specific tax strategies can serve as levers for policy change. Additionally, the ability of tobacco control advocates to articulate the return on investment from spending on tobacco control programmes and quitline services may help inform the decision making process and may be informative for other public health programmes. Finally, the anticipated additional MSA payment to states in 2008 may represent an additional opportunity to advocate for increased tobacco control investment. Future research should investigate whether such trends continue and whether other factors, including political and economic factors, that influence the state decision making process can be identified.

\section{ACKNOWLEDGEMENTS}

The authors thank the North American Quitline Consortium (NAQC) for providing the 2004 survey data for analysis. The 2004 NAQC survey was funded by the American Legacy Foundation. The analyses were funded by grant No 52570 from the Partners with Tobacco Use Research Centers program of the Robert Wood Johnson Foundation and grant No 53133 from the Substance Abuse Policy Research Program of the Robert Wood Johnson Foundation. The authors also thank Stevens Smith, $\mathrm{PhD}$, and Sandra Japuntich for consulting on the data analyses.

\section{Authors' affiliations}

Paula A Keller, University of Wisconsin Center for Tobacco Research and Intervention, University of Wisconsin School of Medicine and Public Health, Madison, WI, USA

Kalsea J Koss, University of Wisconsin Center for Tobacco Research and Intervention, University of Wisconsin School of Medicine and Public Health, Madison, WI, USA (currently at the University of Notre Dame, South Bend, IN, USA) 


\section{What this study adds}

Our findings indicate a relation between cigarette excise tax rates and whether a state had a quitline in 2004. For every dollar increase in the cigarette excise tax rate, the likelihood that the state had a quitline increased 10-fold. Our findings also indicate a relation between per capita quitline operating budgets, per capita state tobacco control expenditures, and cigarette consumption. States that invest more in tobacco control per capita and with higher rates of cigarette consumption invest more in quitline operations per capita. This study adds information on state level factors that may indicate a relation between presence of state quitlines and the level of quitline operations funding. These results may be helpful to state tobacco control programmes and to policy makers as they seek to sustain or increase support for these services.

Timothy B Baker, University of Wisconsin Center for Tobacco Research and Intervention, University of Wisconsin School of Medicine and Public Health, Madison, WI, USA

Linda A Bailey, North American Quitline Consortium, Phoenix, AZ, USA Michael C Fiore, University of Wisconsin Center for Tobacco Research and Intervention, University of Wisconsin School of Medicine and Public Health, Madison, WI, USA

Competing interest statement: PAK, KJK, and $L A B$ have no financial conflicts of interest. TBB has served as a principal investigator or coprincipal investigator for research clinical trials for several pharmaceutical companies, including Glaxo-Wellcome, Pfizer, and Nabi; he does not take honoraria or payments/compensation for services rendered from such corporate entities. Over the past five years (ending in December 2005), MCF has received honoraria for lectures and consulting fees from Pfizer and GlaxoSmithKline; over the past five years, he has served as an investigator on research studies at the University of Wisconsin (UW) that were funded wholly or in part by Pfizer, GlaxoSmithKline, Sanofi-Aventis, and Nabi. In 1998, the UW appointed MCF to a named chair, made possible by an unrestricted gift to UW from GlaxoWellcome.

\section{REFERENCES}

1 Lancaster B. The US National Network of Tobacco Cessation Quitlines: a model of partnership in action, World Conference on Tobacco or Health, July, 2006.

2 Ossip-Klein DJ, McIntosh S. Quitlines in North America: evidence base and applications. Am J Med Sci 2003;326:201-5.

3 Zhu SH, Anderson CM, Tedeschi GJ, et al. Evidence of real-world effectiveness of a telephone quitline for smokers. N Engl J Med 2002;347:1087-93.

4 Stead LF, Perera R, Lancaster T. Telephone counselling for smoking cessation. Cochrane Database Syst Rev 2006;(3):CD002850.

5 Fiore MC, Bailey WC, Cohen SJ. Treating tobacco use and dependence: Clinical Practice Guideline. Rockville, MD: US Department of Health and Human Services, US Public Health Service, 2000.

6 Zhu SH, Rosbrook B, Anderson CM, et al. The demographics of help-seeking for smoking cessation in California and the role of the California Smokers' Helpline. Tob Control 1995;4:s9-s15.
7 Zhu SH, Anderson CM, Johnson CE, et al. A centralised telephone service for tobacco cessation: the California experience. Tob Control 2000;9:|148-55.

8 Swartz SH, Cowan TM, Klayman JE, et al. Use and effectiveness of tobacco telephone counseling and nicotine therapy in Maine. Am J Prev Med 2005;29:288-94.

9 RAND Health. Medicare stop smoking program final report, 31 July 2005.

10 Centers for Disease Control and Prevention. Telephone quitlines: a resource for development, implementation, and evaluation, Final edition. Atlanta, GA: US Department of Health and Human Services, Centers for Disease Control, National Center for Chronic Disease Prevention and Health Promotion, Office on Smoking and Health, 2004.

11 Keller PA, Bailey LA, Koss KJ, et al. Organization, financing, promotion and cost of US quitlines-2004. Am J Prev Med 2007;32:32-7.

12 Gross CP, Soffer B, Bach PB, et al. State expenditures for tobacco-control programs and the tobacco settlement. N Engl J Med 2002;347:1080-6.

13 Frist B. Public health and national security: the critical role of increased federal support. Health Aff (Millwood) 2002;21:1 17-30.

14 Centers for Disease Control and Prevention. Annual smoking-attributable mortality, years of potential life lost, and productivity losses - United States, 1997-2001. MMWR Morb Mortal Wkly Rep 2005;54:625-8.

15 Campaign for Tobacco-Free Kids. A broken promise to our children: The 1998 state tobacco settlement eight years later. Available at: http:// www.tobaccofreekids.org/reports/settlements 2006. Accessed 6 December, 2006.

16 Snyder A, Fallba T, Busch S, et al. Are state legislatures responding to public opinion when allocating funds for tobacco control programs? Health Promot Pract 2004;5:35S-45S.

17 Medoff MH. The political implications of state political ideology: a measure tested. Am J Econ Sociol 1997;56:145-58.

18 Hosmer DW, Lemeshow S. Applied logistic regression, 2nd ed. New York: John Wiley, 2000.

19 Orleans CT. Preventing tobacco-caused cancer: a call to action. Environ Health Perspect 1995; 103:1 149-52.

20 Centers for Disease Control and Prevention. Best practices for comprehensive tobacco control programs -August 1999. Atlanta: US Depart of Health and Human Services, Centers for Disease Control and Prevention, National Center for Chronic Disease Prevention and Health Promotion, Office on Smoking and Health, 1999.

21 US Census Bureau. Annual estimates of the population for the United States: 1 July 2000 to July 1, 2004. Available at: http://ww.census.gov/popest/states/ NST-ann-est.html. Accessed 26 September, 2005.

22 Centers for Disease Control and Prevention. State-specific prevalence of cigarette smoking and quitting among adults - United States, 2004. MMWR Morb Mortal Wkly Rep 2005;54:1124-7.

23 Orzechowski W, Walker RD. The tax burden on tobacco: historical compilation Arlington, VA 2003;37.

24 Health Policy Tracking Service. Securitization of tobacco settlement revenue. Available at: http://www.ncsl.org/programs/fiscal/securtsr.htm. Accessed 31 October, 2005.

25 Tax Policy Center. Tax facts: cigarette rates 2001-2006. Available at: http:// www.taxpolicycenter.org/TaxFacts/TFDB/TFTemplate. $c f m ?$ Docid $=433$. Accessed 26 September, 2005.

26 National Governor's Association. Governors' political affiliations and terms of office, 2004. Available at: http://www.nga.org/cda/files/GOVLIST2004.PDF. Accessed 10 October, 2005.

27 National Conference of State Legislatures. 2004 partisan composition of state legislatures. Available at: http://www.ncsl.org/ncsldb/elect98/ partcmp.cfm?yearsel =2004. Accessed 10 October, 2005.

28 Lav IJ, Johnson N. State budget deficits for fiscal year 2004 are huge and growing. In:Center on budget and policy priorities.Available at: http:// www.cbpp.org/12-23-02sfp.htm. Accessed 5 April, 2006.

29 United States Department of Agriculture NASS. 2002 census of agriculturestate data. Available at: http://www.nass.usda.gov/census/census02/ volume1/us/st99_2_025_025.pdf. Accessed 26 September, 2005. 